
\title{
Predictive value of inflammation-based prognostic scores in patients with metastatic renal cell carcinoma treated with cytoreductive nephrectomy
}

\author{
Hironori Fukuda ${ }^{1}$, Toshio Takagi ${ }^{1}$, Tsunenori Kondo ${ }^{2}$, Satoru Shimizu ${ }^{3}$ and Kazunari \\ Tanabe ${ }^{1}$ \\ ${ }^{1}$ Department of Urology, Tokyo Women's Medical University, Shinjuku-ku, Tokyo, Japan \\ ${ }^{2}$ Department of Urology, Tokyo Women's Medical University Medical Center East, Arakawa-ku, Tokyo, Japan \\ ${ }^{3}$ Department of Medical Education, Tokyo Women's Medical University, Shinjuku-ku, Tokyo, Japan \\ Correspondence to: Toshio Takagi, email: t.takagi1192@gmail.com
}

Keywords: renal cell carcinoma; metastasis; cytoreductive nephrectomy; prognosis; inflammation-based prognostic score Received: July 26, 2017 Accepted: February 10, 2018 Epub: February 16, 2018 Published: March 06, 2018

Copyright: Fukuda et al. This is an open-access article distributed under the terms of the Creative Commons Attribution License 3.0 (CC BY 3.0), which permits unrestricted use, distribution, and reproduction in any medium, provided the original author and source are credited.

\section{ABSTRACT}

Inflammation-based prognostic scores are useful for predicting survival in various cancers. Here, we aimed to determine the most useful inflammationbased prognostic score for predicting survival in patients with metastatic renal cell carcinoma undergoing cytoreductive nephrectomy. We retrospectively analyzed the data of $\mathbf{1 5 2}$ patients who underwent cytoreductive nephrectomy for metastatic renal cell carcinoma between 1986 and 2015. In the multivariate stepwise analysis, the combination of age, Memorial Sloan-Kettering Cancer Center score, histology, sarcomatoid change, clinical nodal stage, brain metastasis, and liver metastasis was a significant predictor for survival (Harrell's concordance index [c-index]: 0.638). The c-index of the combination improved with the addition of an inflammationbased prognostic score: C-reactive protein (c-index: $\mathbf{0 . 6 7 2}$ ), Glasgow prognostic score (c-index: $\mathbf{0 . 6 7 4 )}$, neutrophil-to-lymphocyte ratio (c-index: $\mathbf{0 . 6 8 5}$ ), lymphocyteto-monocyte ratio (c-index: 0.670 ), platelet-to-lymphocyte ratio (c-index: 0.666 ), systemic inflammation response index (c-index: 0.652 ), and systemic immuneinflammation index (c-index: 0.678). The neutrophil-to-lymphocyte ratio provided the greatest improvement in the c-index. Additional multivariate analysis showed that the neutrophil-to-lymphocyte ratio was an independent prognostic factor for survival $(P<0.0001)$. The neutrophil-to-lymphocyte ratio was the most useful inflammationbased prognostic score for predicting survival in patients with metastatic renal cell carcinoma treated with cytoreductive nephrectomy.

\section{INTRODUCTION}

Cancers of the kidney and renal pelvis account for approximately $3 \%$ of all adult tumors. The American Cancer Society estimated that, in 2017, about 63,990 new cases of kidney cancer $(40,610$ in men and 23,380 in women) will occur, and that approximately 14,400 people (9,470 men and 4,930 women) will die from this disease [1]. Renal cell carcinoma (RCC) accounts for the majority of kidney and renal pelvis cancers, and approximately
$30 \%$ of patients with RCC ultimately require systemic therapy for metastatic disease [2].

For patients with metastatic renal cell carcinoma (mRCC), in the cytokine therapy era cytoreductive nephrectomy $(\mathrm{CN})$ of the primary tumor has been shown to improve survival as reported in two randomized trials and a combined analysis [3-5]. After targeted molecular therapies, several agents targeting the vascular endothelial growth factor (VEGF) [6-9] and mammalian target of rapamycin pathways $[10,11]$, were introduced to $\mathrm{mRCC}$ 
treatment, some retrospective studies suggesting similar survival benefit of $\mathrm{CN}$ have existed [12-15], although conflict opinions also have been reported [16]. These controversial results are currently being evaluated by two ongoing randomized trials (CARMENE and SURTIME). In either case, because not all patients with $\mathrm{mRCC}$ will benefit from $\mathrm{CN}$, prognostic factors affecting $\mathrm{mRCC}$ patients should be investigated to optimize the benefits of $\mathrm{CN}$.

It was previously reported that various inflammation-based prognostic scores, such as C-reactive protein (CRP), Glasgow prognostic score (GPS), plateletto-lymphocyte ratio (PLR), and neutrophil-to-lymphocyte ratio (NLR) might be useful for predicting survival in patients with a malignant neoplasm [17-20]. In addition, CRP, GPS, NLR, the systemic inflammation response index (SIRI), and the systemic immune-inflammation index (SII) have been investigated in patients with mRCC, and have been shown to have a prognostic significance [21-25]. However, it is not clear which of these inflammation-based prognostic scores best predicts survival in patients with $\mathrm{mRCC}$ treated with $\mathrm{CN}$.

The aim of the present study was to investigate and compare the predictive accuracy of these various inflammation-based prognostic scores to identify the most useful predictive factor in patients with $\mathrm{mRCC}$ treated with $\mathrm{CN}$.

\section{RESULTS}

\section{Patient characteristics and inflammation-based prognostic scores}

Table 1 shows the patient characteristics of the 152 patients with mRCC who were treated with $\mathrm{CN}$. Because all of these patients had synchronous metastasis at the time of RCC diagnosis, there were no patients with a favorable Memorial Sloan-Kettering Cancer Center (MSKCC) risk score; 106 patients $(70 \%)$ were classified as intermediate risk and 46 patients $(30 \%)$ were classified as poor risk. The treatment details for metastasis existing at $\mathrm{CN}$ were described in Table 2. Furthermore, the values of the various inflammatory prognostic factors are shown in Table 3, including CRP, GPS, NLR, LMR, PLR, SIRI, and SII.

\section{The relationship between clinicopathologic factors including inflammation-based prognostic scores and overall survival in patients with mRCC treated with $\mathbf{C N}$}

During the follow-up period, 92 patients (61\%) died of various causes and 84 patients $(55 \%)$ died of RCC. The results of the univariate analysis for overall survival (OS) are shown in Tables 4 and 5. Table 4 shows that Eastern Cooperative Oncology Group performance status (ECOG-PS) $(P=0.0006)$, MSKCC risk $(P<0.0001)$, histology $(P=0.0099)$, sarcomatoid change $(P=0.0022)$, number of metastatic organs $(P=0.011)$, brain metastasis $(P=0.037)$, and liver metastasis $(0.0015)$ were significantly associated with OS. Table 5 shows that all inflammation-based prognostic scores were significantly associated with OS.

\section{NLR improved the predictive accuracy for overall survival in patients with $\mathrm{mRCC}$ treated with $\mathrm{CN}$ to a greater extent than did other inflammation-based prognostic scores}

Multivariate stepwise Cox's proportional hazards model analysis revealed that the best combination of prognostic factors for OS, excluding inflammation-based prognostic scores, included the following 7 factors (base model): age, MSKCC, histology, sarcomatoid change, clinical nodal stage, brain metastasis, and liver metastasis (Table 4). To evaluate the predictive accuracy for OS, the c-index was calculated. The c-index in the base model was 0.638 . The c-index was improved by the addition of CRP (c-index: 0.672), GPS (c-index: 0.674), NLR (c-index: 0.685), LMR (c-index: 0.670), PLR (c-index: 0.666), SIRI (c-index: 0.652), and SII (c-index: 0.678). NLR improved the c-index to a greater extent than did the other inflammation-based prognostic scores (Figure 1). Multivariate analysis using the base model and NLR revealed that NLR was an independent prognostic factor for OS $(P<0.0001)$ (Table 6).

\section{Analysis of the ideal cutoff value of the NLR}

To detect the ideal cutoff value of NLR for OS in patients with $\mathrm{mRCC}$ treated with $\mathrm{CN}$, receiver operating characteristic (ROC) analysis was performed using the mortality at 40 months after $\mathrm{CN}$, resulting in an NLR value of 3.15. To simplify, we approximated the ideal cutoff value of NLR to a value of 3.0. There were 67 patients with a low NLR value $(<3.0)$ and 85 patients with a high NLR value ( $\geq 3.0$ ). The Kaplan-Meier curves showed a significant difference in the OS rates between patients with a low NLR (median: 59.6 months) and a high NLR (median: 10.3 months) $(P<0.0001)$ (Figure 2).

\section{DISCUSSION}

The present study investigated various predictors, including inflammation-based prognostic scores, of survival in patients with $\mathrm{mRCC}$ who underwent $\mathrm{CN}$. Our findings demonstrate that NLR is the most effective factor among inflammation-based prognostic scores for improving the predictive accuracy of factors related to patient and tumor characteristics.

Although primary tumor resection with $\mathrm{CN}$ has been shown to improve survival in several previous studies of patients with mRCC $[12,13]$, the surgical 
Table 1: Patient characteristics $(N=152)$

\begin{tabular}{|c|c|c|}
\hline Age, years & Median $(95 \% \mathrm{CI})$ & $64.0(61.5-64.8)$ \\
\hline \multicolumn{3}{|l|}{ Sex } \\
\hline Male & $n(\%)$ & $109(72)$ \\
\hline Female & $n(\%)$ & $43(28)$ \\
\hline \multicolumn{3}{|l|}{ ECOG-PS } \\
\hline 0 & $n(\%)$ & $89(59)$ \\
\hline 1 & $n(\%)$ & $43(28)$ \\
\hline 2 & $n(\%)$ & $14(9)$ \\
\hline 3 & $n(\%)$ & $6(4)$ \\
\hline \multicolumn{3}{|l|}{ MSKCC risk } \\
\hline Intermediate & $n(\%)$ & $106(70)$ \\
\hline Poor & $n(\%)$ & $46(30)$ \\
\hline \multicolumn{3}{|l|}{ Histology } \\
\hline Clear cell carcinoma & $n(\%)$ & $138(91)$ \\
\hline Non-clear cell carcinoma & $n(\%)$ & $14(9)$ \\
\hline Sarcomatoid change & $n(\%)$ & $22(14)$ \\
\hline
\end{tabular}

Abbreviations: ECOG-PS, Eastern Cooperative Oncology Group performance status; MSKCC, Memorial Sloan-Kettering Cancer Center.

Table 2: Treatment for metastasis existing at cytoreductive nephrectomy

\begin{tabular}{lc}
\hline Systemic treatment, $n(\%)$ & $36(24)$ \\
Sunitinib & $16(11)$ \\
Sorafenib & $4(3)$ \\
Temsirolimus & $5(3)$ \\
Pazopanib & $2(1)$ \\
Axitinib & $52(34)$ \\
Interferon & $5(3)$ \\
IL2 & $2(1)$ \\
Interferon + IL2 & $6(4)$ \\
Metastasectomy, $n(\%)$ & $6(4)$ \\
EBRT, $n(\%)$ & $14(9)$ \\
None, $n(\%)$ & $4(3)$ \\
Unknown, $n(\%)$ & $(3)$ \\
\hline
\end{tabular}

Abbreviations: IL2, interleukin-2; EBRT, external beam radiation therapy.

procedure is invasive and has potential risks. To determine the best candidates for $\mathrm{CN}$, prognostic factors for survival in patients with $\mathrm{mRCC}$ treated with $\mathrm{CN}$ should be considered. Numerous studies have previously reported that inflammation-based prognostic scores might be useful for predicting survival in patients with various malignancies. The GPS is a selective combination of CRP and albumin serum levels that has been examined and validated in more than 60 studies for a variety of cancers $[17,26]$. The PLR has been identified as an independent prognostic marker for survival in breast cancer patients. Elevated preoperative
PLR levels have been associated with cause-specific survival in univariate analysis (hazard ratio [HR]: 2.75, 95\% confidence interval [CI]: $1.57-4.83, P<0.001)$ and multivariate analysis (HR: 2.03, 95\% CI: 1.03-4.02, $P=0.042$ ) [18].

Additionally, the usefulness of inflammationbased prognostic scores has been reported in patients with mRCC. In patients with mRCC treated with first line sunitinib therapy, patients with a low SII had a significantly longer OS than did those with a high SII (median OS: 43.6 months vs. 13.5 months, $P<0.0001$ ) [25]. In patients with $\mathrm{mRCC}$ treated with $\mathrm{CN}$, the SIRI 
Table 3: The value of the inflammation-based prognostic scores

\begin{tabular}{lcc}
\hline CRP, mg/dl & Median $(95 \% \mathrm{CI})$ & $2.4(3.9-5.7)$ \\
GPS & $n(\%)$ & $47(31)$ \\
0 & $n(\%)$ & $59(39)$ \\
1 & $n(\%)$ & $46(30)$ \\
2 & Median $(95 \% \mathrm{CI})$ & $3.2(1.1-10.8)$ \\
NLR & Median $(95 \% \mathrm{CI})$ & $3.4(3.5-4.2)$ \\
LMR & Median $(95 \% \mathrm{CI})$ & $195(200-233)$ \\
PLR & $n(\%)$ & $29(19)$ \\
SIRI & $n(\%)$ & $68(45)$ \\
0 & $n(\%)$ & $55(36)$ \\
1 & Median $(95 \% \mathrm{CI})$ & $819(920-1168)$ \\
\hline
\end{tabular}

Abbreviations: CRP, C-reactive protein; GPS, Glasgow prognostic score; NLR, neutrophil to lymphocyte ratio; LMR, lymphocyte to monocyte ratio; PLR, platelet to lymphocyte ratio; SIRI, systemic inflammation response index; SII, systemic immune-inflammation index.

Table 4: Univariate and multivariate stepwise analysis of prognostic factors other than inflammation-based prognostic scores for overall survival in patients with metastatic renal cell carcinoma treated with cytoreductive nephrectomy

\begin{tabular}{|c|c|c|c|c|c|c|}
\hline & $\begin{array}{c}\text { Univariate } \\
\text { analysis } \\
\text { HR }\end{array}$ & $95 \%$ CI & $P$ value & $\begin{array}{c}\text { Stepwise } \\
\text { analysis } \\
\text { HR }\end{array}$ & $95 \%$ CI & $P$ value \\
\hline Age & 1.02 & $0.999-1.04$ & 0.064 & 1.03 & $1.009-1.057$ & 0.0062 \\
\hline Sex & & & 0.27 & - & - & - \\
\hline Male & 1.00 & Reference & & - & - & - \\
\hline Female & 1.29 & $0.816-1.98$ & & - & - & - \\
\hline ECOG-PS & & & 0.0006 & - & - & - \\
\hline 0,1 & 1.00 & Reference & & - & - & - \\
\hline$\geq 2$ & 2.83 & $1.61-4.70$ & & - & - & - \\
\hline MSKCC risk & & & $<0.0001$ & & & $<0.0001$ \\
\hline Intermediate & 1.00 & Reference & & 1.00 & Reference & \\
\hline Poor & 2.50 & $1.63-3.79$ & & 2.65 & $1.71-4.08$ & \\
\hline Histology & & & 0.0099 & & & 0.0008 \\
\hline Clear cell carcinoma & 1.00 & Reference & & 1.00 & Reference & \\
\hline Non-clear cell carcinoma & 2.74 & $1.30-5.23$ & & 4.28 & $1.91-8.83$ & \\
\hline Sarcomatoid change & 2.59 & $1.44-4.39$ & 0.0022 & 3.83 & $2.06-6.81$ & \\
\hline Clinical T stage & & & 0.23 & & & - \\
\hline cT1-2 & 1.00 & Reference & & - & - & - \\
\hline cT3-4 & 1.40 & $0.817-2.58$ & & - & - & - \\
\hline Clinical nodal stage & & & 0.17 & & & 0.85 \\
\hline No & 1.00 & Reference & & 1.00 & Reference & \\
\hline N1 & 0.779 & $0.272-1.76$ & & 0.84 & $0.290-1.91$ & \\
\hline $\mathrm{N} 2$ & 1.57 & $0.934-2.53$ & & & $0.643-1.83$ & \\
\hline Primary tumor size & 1.006 & $1.00-1.01$ & 0.050 & - & - & - \\
\hline
\end{tabular}


Number of metastatic organs

0.011

\begin{tabular}{|c|c|c|c|c|c|c|}
\hline 1 & 1.00 & Reference & & - & - & - \\
\hline$\geq 2$ & 1.78 & $1.15-2.72$ & & - & - & - \\
\hline Brain metastasis & 3.65 & $1.10-8.99$ & 0.037 & 6.97 & $2.00-18.6$ & 0.0046 \\
\hline Liver metastasis & 3.89 & $1.77-7.64$ & 0.0015 & 4.42 & $1.95-9.10$ & 0.0008 \\
\hline
\end{tabular}

Abbreviations: HR, hazard ratio; CI, confidence interval; ECOG-PS, Eastern Cooperative Oncology Group performance status; MSKCC, Memorial Sloan-Kettering Cancer Center.

Table 5: Univariate analysis of inflammation-based prognostic scores for overall survival in patients with metastatic renal cell carcinoma treated with cytoreductive nephrectomy

\begin{tabular}{lccc}
\hline Univariate analysis & HR & 95\% CI & P value \\
\hline CRP & 1.08 & $1.05-1.12$ & \\
GPS & & & $<0.0001$ \\
0 & 1.00 & Reference & \\
1 & 1.89 & $1.12-3.21$ & \\
2 & 3.54 & $2.07-6.14$ & $<01$ \\
NLR & 1.32 & $1.19-1.45$ & $<0.0001$ \\
LMR & 0.814 & $0.717-0.914$ & $<0.0001$ \\
PLR & 1.0004 & $1.0002-1.0004$ & 0.0004 \\
SIRI & & & \\
0 & 1.00 & Reference & \\
1 & 3.30 & $1.70-7.21$ & \\
2 & 3.42 & $1.69-7.67$ & \\
SII & 1.0006 & $1.0003-1.0009$ & \\
\hline
\end{tabular}

Abbreviations: HR, hazard ratio; CI, confidence interval; CRP, C-reactive protein; GPS, Glasgow prognostic score; NLR, neutrophil to lymphocyte ratio; LMR, lymphocyte to monocyte ratio; PLR, platelet to lymphocyte ratio; SIRI, systemic inflammation response index; SII, systemic immune-inflammation index.

\begin{tabular}{|c|c|c|}
\hline \multirow{4}{*}{ The c-index of the base model } & \multirow{2}{*}{\multicolumn{2}{|c|}{ C-index }} \\
\hline & & \\
\hline & The base model with CRP & 0.672 \\
\hline & The base model with GPS & 0.674 \\
\hline \multirow[t]{5}{*}{0.638} & The base model with NLR & 0.685 \\
\hline & The base model with LMR & 0.670 \\
\hline & The base model with PLR & 0.666 \\
\hline & The base model with SIRI & 0.652 \\
\hline & The base model with SII & 0.678 \\
\hline
\end{tabular}

Figure 1: The c-index of the base model and the base model with each inflammation-based prognostic score. Abbreviations: c-index, concordance index; CRP, C-reactive protein; GPS, Glasgow prognostic score; NLR, neutrophil-to-lymphocyte ratio; LMR, lymphocyte-to-monocyte ratio; PLR, platelet-to-lymphocyte ratio; SIRI, systemic inflammation response index; SII, systemic immuneinflammation index. 
Table 6: Multivariate analysis of base model with neutrophil to lymphocyte ratio for overall survival in patients with metastatic renal cell carcinoma treated with cytoreductive nephrectomy

\begin{tabular}{lccc}
\hline Multivariate analysis & HR & $\mathbf{9 5 \%}$ CI & P value \\
\hline Age & 1.03 & $1.006-1.054$ & 0.014 \\
MSKCC risk & & & 0.0003 \\
Intermediate & 1.00 & Reference & \\
Poor & 2.38 & $1.51-3.72$ & 0.0016 \\
Histology & & & \\
Clear cell carcinoma & 1.00 & Reference & \\
Non-clear cell carcinoma & 3.86 & $1.73-7.91$ & 0.0004 \\
Sarcomatoid change & 3.24 & $1.74-5.77$ & 0.18 \\
Clinical nodal stage & & & \\
N0 & 1.00 & Reference & \\
N1 & 0.44 & $0.141-1.09$ & \\
N2 & 1.11 & $0.646-1.82$ & 0.0035 \\
Brain metastasis & 7.46 & $2.15-19.9$ & $<0.0001$ \\
Liver metastasis & 6.25 & $2.70-13.3$ & $<0.0001$ \\
NLR & 1.33 & $1.19-1.49$ & \\
\hline
\end{tabular}

Abbreviations: HR, hazard ratio; CI, confidence interval; MSKCC, Memorial Sloan-Kettering Cancer Center; NLR, neutrophil to lymphocyte ratio.

appeared to be an independent prognostic factor for OS and was significantly associated with aggressive tumor behavior [23]. Despite these studies, it is not clear which inflammation-based prognostic scores best predict survival in patients with mRCC treated with $\mathrm{CN}$.
The present study identified NLR as the best predictor among the various inflammation-based prognostic scores that we evaluated for predicting survival in patients with $\mathrm{mRCC}$ who underwent $\mathrm{CN}$. Patients with a low NLR $(<3.0)$ had a significantly longer OS than

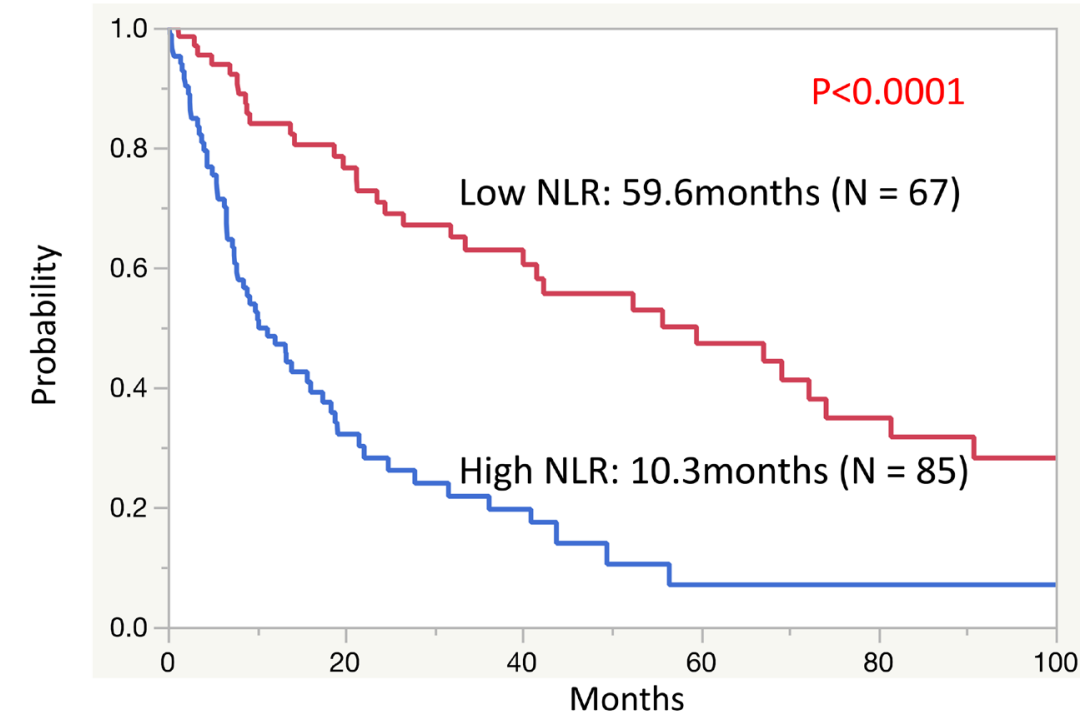

Number of patients at risk

$\begin{array}{llllccc}\text { Low NLR } & 67 & 41 & 27 & 18 & 12 & 7 \\ \text { High NLR } & 85 & 18 & 10 & 3 & 2 & 1\end{array}$

Figure 2: The Kaplan-Meier curves of the overall survival rates between patients with a low neutrophil-to-lymphocyte ratio (NLR) and a high NLR. 
Table 7: The criteria of the Glasgow prognostic score and the systemic inflammation response index

\section{(A) Glasgow prognostic score}

\begin{tabular}{ll}
\hline & Points \\
\hline C-reactive protein $\leq 1.0 \mathrm{mg} / \mathrm{dl}$ and albumin $\geq 3.5 \mathrm{~g} / \mathrm{dl}$ & 0 \\
C-reactive protein $>1.0 \mathrm{mg} / \mathrm{dl}$ or albumin $<3.5 \mathrm{~g} / \mathrm{dl}$ & 1 \\
C-reactive protein $>1.0 \mathrm{mg} / \mathrm{dl}$ and albumin $<3.5 \mathrm{~g} / \mathrm{dl}$ & 2 \\
\hline
\end{tabular}

\section{(B) Systemic inflammation response index}

\begin{tabular}{ll}
\hline & Points \\
\hline Hemoglobin $\geq 137 / 116 \mathrm{gl}^{-1}($ male/female $)$ and LMR $\geq 3.23$ & 0 \\
Hemoglobin $\geq 137 / 116 \mathrm{gl}^{-1}($ male/female $)$ or LMR $\geq 3.23$ & 1 \\
Hemoglobin $<137 / 116 \mathrm{gl}^{-1}($ male/female) and LMR $<3.23$ & 2 \\
\hline
\end{tabular}

Abbreviation: LMR, lymphocyte to monocyte ratio.

did those patients with a high NLR $(\geq 3.0)$ (median OS: 59.6 months vs. 10.3 months, respectively) $(P<0.0001)$. The usefulness of NLR for predicting survival has been reported in many previous studies of various cancers [20, 27-30]. In patients with RCC, the preoperative NLR levels in patients with a localized nonclear-cell RCC was shown to be significantly associated with disease-free survival in univariate analysis (HR: $1.15, P=0.028$ ) and in multivariate analysis (HR: 1.17, $P=0.022$ ) [31]. In patients with $\mathrm{mRCC}$ treated with $\mathrm{CN}$, it was reported that a high NLR $(\geq 4.0)$ was significantly associated with poor outcomes. The median OS of the patients with high NLR in that study $(\geq 4.0)$ was 10.2 months, which was significantly shorter than that of the patients with a low NLR (<4.0) (36.5 months, $P=0.002)$ [24].

The association between inflammation and the cancer progression has been investigated in many previous studies. NLR is a marker of inflammation and immunity. Neutrophils promote angiogenesis and inhibit the antitumor immune system response, resulting in tumor growth $[32,33]$. VEGF, secreted by neutrophils, induces angiogenesis and promotes tumor growth, recurrence, invasion, and metastasis [34, 35]. On the other hand, lymphocytes are essential in tumor defense. Lymphocytes can elicit cytotoxic cell death and interfere with tumor cell proliferation and migration [27]. In patients with RCC, high levels of lymphocytic attractant chemokine expression have been shown to be a favorable prognostic factor [36]. Therefore, a high NLR, which reflects an increased neutrophil count or a decreased lymphocyte count, can be a useful prognostic factor in cancer patients.

There are some limitations of the present study, including its retrospective and single-center study design. In addition, we were not able to assess the data of all inflammation-based prognostic scores in all patients because some scores were unknown or not measured. Nevertheless, the present study, to our best knowledge, is the first study investigating which inflammation-based prognostic score can best predict survival in patients with
mRCC treated with CN. Future large-scale prospective multi-center studies are needed to confirm our findings.

\section{MATERIALS AND METHODS}

\section{Patients}

After approval by the institutional review board, the present study retrospectively reviewed the medical records of patients at our hospital and identified 152 patients diagnosed with mRCC who were treated with CN between March 1986 and August 2015. The median follow-up period was 14 months, and the survival data was collected until 100 months after CN. Tumor stage was determined according to the 2009 TNM classification [37]. Pathological diagnoses were made according to the 2016 World Health Organization classification [38]. Stratification of prognostic risk was done according to the MSKCC risk classification [39].

\section{Measurements and definitions}

Clinical, laboratory, and survival data were collected by reviewing the electronic medical records of the patients. Pathologic data were obtained from nephrectomy specimens. Surgical specimens were processed according to standard pathological procedures. All specimens were histologically confirmed to be RCC.

We examined the seven inflammation-based prognostic scores, including CRP, GPS, NLR, LMR, PLR, SIRI, and SII. The GPS was calculated as previously described [17]. Briefly, patients with an elevated CRP concentration $(>1.0 \mathrm{mg} / \mathrm{dL})$ and a decreased albumin concentration $(<3.5 \mathrm{~g} / \mathrm{dL})$ were assigned a score of 2. Patients with an elevated CRP concentration $(>1.0$ $\mathrm{mg} / \mathrm{dL})$ or a decreased albumin concentration $(<3.5$ $\mathrm{g} / \mathrm{dL}$ ) were assigned a score of 1 , and patients with a CRP concentration of $\leq 1.0 \mathrm{mg} / \mathrm{dL}$ and an albumin concentration of $\geq 3.5 \mathrm{~g} / \mathrm{dL}$ were assigned a score of 0 
(Table 7A). The NLR was defined as the serum absolute neutrophil count divided by the lymphocyte count in the peripheral blood [40]. The LMR was defined as the serum absolute lymphocyte count divided by the monocyte count in the peripheral blood [41]. The PLR was calculated as the absolute platelet count measured in $\times 10^{9} \mathrm{~L}^{-1}$ divided by the absolute lymphocyte count measured in $\times 10^{9} \mathrm{~L}^{-1}$ [18]. The SIRI was defined as follows: patients with both elevated hemoglobin and elevated LMR $(\geq 137 / 116$ $\mathrm{gL}^{-1}$ and $\geq 3.23$, respectively) were allotted to group 0 ; patients with either elevated hemoglobin or elevated LMR were allotted to group 1; and patients with both a decreased hemoglobin and a decreased LMR $(<137 / 116$ $\mathrm{gL}^{-1}$ and $<3.23$, respectively) were assigned to group 2 (Table 7B) [23]. The SII was defined as follows: SII $=\mathrm{P} \times$ $\mathrm{N} / \mathrm{L}$, where $\mathrm{P}, \mathrm{N}$, and $\mathrm{L}$ were the preoperative peripheral platelet, neutrophil, and lymphocyte counts, respectively $[25,42]$.

\section{Statistical analysis:}

Survival analysis was performed using the Cox's proportional hazards model. Multivariate stepwise Cox's proportional hazards model analysis was performed to select the best combination of prognostic factors. The predictive accuracy was evaluated using Harrel's concordance index (c-index) [43]. A ROC curve was performed to estimate the optimal cut-off value. OS curves were estimated using the Kaplan-Meier method and compared using the log-rank test. A difference was considered significant at $P<0.05$. Statistical analyses were performed using JMP 11.0.0 (SAS Institute, Cary, NC, USA) and SAS v.9.4 (SAS Institute, Cary, NC, USA).

\section{Abbreviations}

c-index: concordance index; $\mathrm{CI}$ : confidence interval; $\mathrm{CN}$ : cytoreductive nephrectomy; CRP: C-reactive protein; GPS: Glasgow prognostic score; HR: hazard ratio; mRCC: metastatic renal cell carcinoma; MSKCC: Memorial Sloan-Kettering Cancer Center; NLR: neutrophil-to-lymphocyte ratio; OS: overall survival; PLR: platelet-to-lymphocyte ratio; RCC: renal cell carcinoma; ROC: receiver operating characteristics; SII: systemic immune-inflammation index; SIRI: systemic inflammation response index; VEGF: vascular endothelial growth factor.

\section{Author contributions}

HF and TT designed the research; HF, TT, TK, and KT conducted the research; HF and SS analyzed data; HF and TT wrote the draft; and all authors read, reviewed, and approved the final manuscript. TT had primary responsibility for all final content.

\section{ACKNOWLEDGMENTS}

The authors thank Editage for English language editing and Nobuko Hata for secretarial assistance.

\section{CONFLICTS OF INTEREST}

TK previously received hororarium from Pfizer, Novartis, Ono, and Bristol Myers Squib.

\section{FUNDING}

None.

\section{REFERENCES}

1. Siegel RL, Miller KD, Jemal A. Cancer Statistics, 2017. CA Cancer J Clin. 2017; 67:7-30. https://doi.org/10.3322/ caac. 21387.

2. Lam JS, Shvarts O, Leppert JT, Figlin RA, Belldegrun AS. Renal cell carcinoma 2005: new frontiers in staging, prognostication and targeted molecular therapy. J Urol. 2005; 173:1853-62. https://doi.org/10.1097/01. ju.0000165693.68449.c3.

3. Flanigan RC, Salmon SE, Blumenstein BA, Bearman SI, Roy V, McGrath PC, Caton JR Jr, Munshi N, Crawford ED. Nephrectomy followed by interferon alfa-2b compared with interferon alfa-2b alone for metastatic renal-cell cancer. $\mathrm{N}$ Engl J Med. 2001; 345:1655-59. https://doi.org/10.1056/ NEJMoa003013.

4. Mickisch GH, Garin A, van Poppel H, de Prijck L, Sylvester R, and European Organisation for Research and Treatment of Cancer (EORTC) Genitourinary Group. Radical nephrectomy plus interferon-alfa-based immunotherapy compared with interferon alfa alone in metastatic renal-cell carcinoma: a randomised trial. Lancet. 2001; 358:966-70. https://doi.org/10.1016/S0140-6736(01)06103-7.

5. Flanigan RC, Mickisch G, Sylvester R, Tangen C, Van Poppel H, Crawford ED. Cytoreductive nephrectomy in patients with metastatic renal cancer: a combined analysis. J Urol. 2004; 171:1071-76. https://doi.org/10.1097/01. ju.0000110610.61545.ae.

6. Escudier B, Eisen T, Stadler WM, Szczylik C, Oudard S, Siebels M, Negrier S, Chevreau C, Solska E, Desai AA, Rolland F, Demkow T, Hutson TE, et al, and TARGET Study Group. Sorafenib in advanced clear-cell renal-cell carcinoma. N Engl J Med. 2007; 356:125-34. https://doi. org/10.1056/NEJMoa060655.

7. Motzer RJ, Rini BI, Bukowski RM, Curti BD, George DJ, Hudes GR, Redman BG, Margolin KA, Merchan JR, Wilding G, Ginsberg MS, Bacik J, Kim ST, et al. Sunitinib in patients with metastatic renal cell carcinoma. JAMA. 2006; 295:2516-24. https://doi.org/10.1001/ jama.295.21.2516. 
8. Sternberg CN, Davis ID, Mardiak J, Szczylik C, Lee E, Wagstaff J, Barrios CH, Salman P, Gladkov OA, Kavina A, Zarbá JJ, Chen M, McCann L, et al. Pazopanib in locally advanced or metastatic renal cell carcinoma: results of a randomized phase III trial. J Clin Oncol. 2010; 28:1061-68. https://doi.org/10.1200/JCO.2009.23.9764.

9. Karam JA, Devine CE, Urbauer DL, Lozano M, Maity T, Ahrar K, Tamboli P, Tannir NM, Wood CG. Phase 2 trial of neoadjuvant axitinib in patients with locally advanced nonmetastatic clear cell renal cell carcinoma. Eur Urol. 2014; 66:874-80. https://doi.org/10.1016/j. eururo.2014.01.035.

10. Motzer RJ, Escudier B, Oudard S, Hutson TE, Porta C, Bracarda S, Grünwald V, Thompson JA, Figlin RA, Hollaender N, Urbanowitz G, Berg WJ, Kay A, et al, and RECORD-1 Study Group. Efficacy of everolimus in advanced renal cell carcinoma: a double-blind, randomised, placebo-controlled phase III trial. Lancet. 2008; 372:449 56. https://doi.org/10.1016/S0140-6736(08)61039-9.

11. Hudes G, Carducci M, Tomczak P, Dutcher J, Figlin R, Kapoor A, Staroslawska E, Sosman J, McDermott D, Bodrogi I, Kovacevic Z, Lesovoy V, Schmidt-Wolf IG, et al, and Global ARCC Trial. Temsirolimus, interferon alfa, or both for advanced renal-cell carcinoma. N Engl J Med. 2007; 356:2271-81. https://doi.org/10.1056/NEJMoa066838.

12. Choueiri TK, Xie W, Kollmannsberger C, North S, Knox JJ, Lampard JG, McDermott DF, Rini BI, Heng DY. The impact of cytoreductive nephrectomy on survival of patients with metastatic renal cell carcinoma receiving vascular endothelial growth factor targeted therapy. J Urol. 2011; 185:60-66. https://doi.org/10.1016/j.juro.2010.09.012.

13. Heng DY, Wells JC, Rini BI, Beuselinck B, Lee JL, Knox JJ, Bjarnason GA, Pal SK, Kollmannsberger CK, Yuasa T, Srinivas S, Donskov F, Bamias A, et al. Cytoreductive nephrectomy in patients with synchronous metastases from renal cell carcinoma: results from the International Metastatic Renal Cell Carcinoma Database Consortium. Eur Urol. 2014; 66:704-10. https://doi.org/10.1016/j. eururo.2014.05.034.

14. Mathieu R, Pignot G, Ingles A, Crepel M, Bigot P, Bernhard JC, Joly F, Guy L, Ravaud A, Azzouzi AR, Gravis G, Chevreau C, Zini L, et al. Nephrectomy improves overall survival in patients with metastatic renal cell carcinoma in cases of favorable MSKCC or ECOG prognostic features. Urol Oncol. 2015; 33:339.e9-15. https://doi.org/10.1016/j. urolonc.2015.05.014

15. Petrelli F, Coinu A, Vavassori I, Cabiddu M, Borgonovo K, Ghilardi M, Lonati V, Barni S. Cytoreductive nephrectomy in metastatic renal cell carcinoma treated with targeted therapies: a systematic review with a meta-analysis. Clin Genitourin Cancer. 2016; 14:465-72. https://doi. org/10.1016/j.clgc.2016.04.001.

16. You D, Jeong IG, Ahn JH, Lee DH, Lee JL, Hong JH, Ahn H, Kim CS. The value of cytoreductive nephrectomy for metastatic renal cell carcinoma in the era of targeted therapy. J Urol. 2011; 185:54-59. https://doi.org/10.1016/j. juro.2010.09.018.

17. McMillan DC. An inflammation-based prognostic score and its role in the nutrition-based management of patients with cancer. Proc Nutr Soc. 2008; 67:257-62. https://doi. org/10.1017/S0029665108007131.

18. Krenn-Pilko S, Langsenlehner U, Thurner EM, Stojakovic T, Pichler M, Gerger A, Kapp KS, Langsenlehner T. The elevated preoperative platelet-to-lymphocyte ratio predicts poor prognosis in breast cancer patients. Br J Cancer. 2014; 110:2524-30. https://doi.org/10.1038/bjc.2014.163.

19. Zhu L, Li X, Shen Y, Cao Y, Fang X, Chen J, Yuan Y. A new prognostic score based on the systemic inflammatory response in patients with inoperable non-small-cell lung cancer. Onco Targets Ther. 2016; 9:4879-86. https://doi. org/10.2147/OTT.S107279.

20. Chen N, Liu S, Huang L, Li W, Yang W, Cong T, Ding L, Qiu M. Prognostic significance of neutrophil-to-lymphocyte ratio in patients with malignant pleural mesothelioma: a meta-analysis. Oncotarget. 2017; 8:57460-69. https://doi. org/10.18632/oncotarget.15404.

21. Saito K, Tatokoro M, Fujii Y, Iimura Y, Koga F, Kawakami S, Kihara K. Impact of C-reactive protein kinetics on survival of patients with metastatic renal cell carcinoma. Eur Urol. 2009; 55:1145-54. https://doi. org/10.1016/j.eururo.2008.10.012.

22. Lamb GW, Aitchison M, Ramsey S, Housley SL, McMillan DC. Clinical utility of the Glasgow Prognostic Score in patients undergoing curative nephrectomy for renal clear cell cancer: basis of new prognostic scoring systems. Br J Cancer. 2012; 106:279-83. https://doi.org/10.1038/ bjc.2011.556.

23. Gu L, Ma X, Wang L, Li H, Chen L, Li X, Zhang Y, Xie Y, Zhang X. Prognostic value of a systemic inflammatory response index in metastatic renal cell carcinoma and construction of a predictive model. Oncotarget. 2017; 8:52094-103. https://doi.org/10.18632/oncotarget.10626.

24. Ohno Y, Nakashima J, Ohori M, Tanaka A, Hashimoto T, Gondo T, Hatano T, Tachibana M. Clinical variables for predicting metastatic renal cell carcinoma patients who might not benefit from cytoreductive nephrectomy: neutrophil-to-lymphocyte ratio and performance status. Int J Clin Oncol. 2014; 19:139-45. https://doi.org/10.1007/ s10147-012-0514-5.

25. Lolli C, Basso U, Derosa L, Scarpi E, Sava T, Santoni M, Crabb SJ, Massari F, Aieta M, Conteduca V, Maruzzo M, La Russa F, Wheater M, et al. Systemic immuneinflammation index predicts the clinical outcome in patients with metastatic renal cell cancer treated with sunitinib. Oncotarget. 2016; 7:54564-71. https://doi.org/10.18632/ oncotarget.10515.

26. McMillan DC. The systemic inflammation-based Glasgow Prognostic Score: a decade of experience in patients with cancer. Cancer Treat Rev. 2013; 39:534-40. https://doi. org/10.1016/j.ctrv.2012.08.003. 
27. Chen Y, Yan H, Wang Y, Shi Y, Dai G. Significance of baseline and change in neutrophil-to-lymphocyte ratio in predicting prognosis: a retrospective analysis in advanced pancreatic ductal adenocarcinoma. Sci Rep. 2017; 7:753. https://doi.org/10.1038/s41598-017-00859-5.

28. Yang Z, Gu J, Guo C, Li X, Yang W. Preoperative neutrophil-to-lymphocyte ratio is a predictor of survival of epithelial ovarian cancer: a systemic review and metaanalysis of observational studies. Oncotarget. 2017; 8:46414-24. https://doi.org/10.18632/oncotarget.16793.

29. Deng M, Ma X, Liang X, Zhu C, Wang M. Are pretreatment neutrophil-lymphocyte ratio and platelet-lymphocyte ratio useful in predicting the outcomes of patients with smallcell lung cancer? Oncotarget. 2017; 8:37200-07. https://doi. org/10.18632/oncotarget.16553.

30. Li X, Ma X, Tang L, Wang B, Chen L, Zhang F, Zhang X. Prognostic value of neutrophil-to-lymphocyte ratio in urothelial carcinoma of the upper urinary tract and bladder: a systemic review and meta-analysis. Oncotarget. 2017; 8:62681-92. https://doi.org/10.18632/oncotarget.17467.

31. de Martino M, Pantuck AJ, Hofbauer S, Waldert M, Shariat SF, Belldegrun AS, Klatte T. Prognostic impact of preoperative neutrophil-to-lymphocyte ratio in localized nonclear cell renal cell carcinoma. J Urol. 2013; 190:19992004. https://doi.org/10.1016/j.juro.2013.06.082.

32. Grivennikov SI, Greten FR, Karin M. Immunity, inflammation, and cancer. Cell. 2010; 140:883-99. https:// doi.org/10.1016/j.cell.2010.01.025.

33. Coussens LM, Werb Z. Inflammation and cancer. Nature. 2002; 420:860-67. https://doi.org/10.1038/nature01322.

34. Wang W, Ma X, Shi Z, Zhang P, Ding D, Huang H, Saiyin H, Chen T, Lu P, Wang N, Yu H, Sun J, Zheng S, et al. Epidermal growth factor receptor pathway polymorphisms and the prognosis of hepatocellular carcinoma. Am J Cancer Res. 2014; 5:396-410.

35. Li X, Han Z, Cheng Z, Yu J, Liu S, Yu X, Liang P. Preoperative neutrophil-to-lymphocyte ratio is a predictor of recurrence following thermal ablation for recurrent hepatocellular carcinoma: a retrospective analysis. PLoS One. 2014; 9:e110546. https://doi.org/10.1371/journal. pone. 0110546 .
36. Kondo $\mathrm{T}$, Ito $\mathrm{F}$, Nakazawa $\mathrm{H}$, Horita $\mathrm{S}$, Osaka $\mathrm{Y}$, Toma H. High expression of chemokine gene as a favorable prognostic factor in renal cell carcinoma. J Urol. 2004; 171:2171-75. https://doi.org/10.1097/01. ju.0000127726.25609.87.

37. Sobin LH, Gospodarowicz MK, Wittekind C, and UICC International Union Against Cancer. TNM classification of malignant tumours. 7th ed. 2009. Chichester, West Sussex, UK; Hoboken, NJ: Wiley-Blackwell; 2010.

38. Moch H, Cubilla AL, Humphrey PA, Reuter VE, Ulbright TM. The 2016 WHO Classification of tumours of the urinary system and male genital organs-Part A: renal, penile, and testicular tumours. Eur Urol. 2016; 70:93-105. https://doi.org/10.1016/j.eururo.2016.02.029.

39. Motzer RJ, Bacik J, Murphy BA, Russo P, Mazumdar M. Interferon-alfa as a comparative treatment for clinical trials of new therapies against advanced renal cell carcinoma. J Clin Oncol. 2002; 20:289-96. https://doi.org/10.1200/ JCO.2002.20.1.289.

40. Proctor MJ, Morrison DS, Talwar D, Balmer SM, Fletcher CD, O'Reilly DS, Foulis AK, Horgan PG, McMillan DC. A comparison of inflammation-based prognostic scores in patients with cancer. A Glasgow Inflammation Outcome Study. Eur J Cancer. 2011; 47:2633-41. https://doi.org/10.1016/j.ejca.2011.03.028.

41. Chang Y, An H, Xu L, Zhu Y, Yang Y, Lin Z, Xu J. Systemic inflammation score predicts postoperative prognosis of patients with clear-cell renal cell carcinoma. Br J Cancer. 2015; 113:626-33. https://doi.org/10.1038/bjc.2015.241.

42. Hu B, Yang XR, Xu Y, Sun YF, Sun C, Guo W, Zhang X, Wang WM, Qiu SJ, Zhou J, Fan J. Systemic immuneinflammation index predicts prognosis of patients after curative resection for hepatocellular carcinoma. Clin Cancer Res. 2014; 20:6212-22. https://doi.org/10.1158/1078-0432. CCR-14-0442.

43. Harrell FE Jr, Califf RM, Pryor DB, Lee KL, Rosati RA. Evaluating the yield of medical tests. JAMA. 1982; 247:2543-46. https://doi.org/10.1001/ jama.1982.03320430047030. 